\title{
Suitability of Pedigree Method for Improving Seed Cotton Yield and Fiber Quality Traits
}

\section{Abia Younas ( $\nabla$ abiayounas@gmail.com )}

AARI: Ayub Agricultural Research Institute https://orcid.org/0000-0001-9974-1041

\section{Farrukh Illahi}

Ayub Agricultural Research Institute

\section{Ghulam Sarwar}

Ayub Agricultural Research Institute

Iram Sharif

Ayub Agricultural Research Institute

\section{Shahid Munir Chohan}

Ayub Agricultural Research Institute

\section{Research}

Keywords: pedigree method, GOT\%, fiber quality, seed cotton yield per plant, gene action

Posted Date: April 5th, 2021

DOI: https://doi.org/10.21203/rs.3.rs-354280/v1

License: (c) (i) This work is licensed under a Creative Commons Attribution 4.0 International License. Read Full License 


\section{Abstract}

Background: Cotton is grown around the globe for its fiber, which consists of unicellular seed trichome. Converging decent fiber quality and good fiber yield in cotton varieties is crucial for textile industry of any country. Pedigree method is mostly used for developing cotton varieties in Pakistan. Suitability of pedigree method for developing cotton variety is accessed in an experiment. Genotypic variance, phenotypic variance, heritability, co-heritability, genetic advance, mean comparison and correlation analysis was carried out of nine breeding lines of in fifth filial generation. Gene action was thus determined to target the traits for further yield and quality improvement of cotton fiber.

Results: Substantial genetic variability existed in $\mathrm{F}_{5}$ lines. Genotypic and phenotypic variances had less differences and phenotypic variances were higher than genotypic variance indicating influence of environment on the final expression of the traits. All traits had medium to high heritability. Seed cotton yield per plant came up with high genetic advance and high heritability indicating additive gene action and can be improved by selection. Mean comparison indicated more variation for GOT\% compared to other traits. Correlation analysis indicated selecting more sympodial branches for improving seed cotton yield per plant and selecting more monopodial branches for improving fiber fineness and fiber length. However, co-heritability had high value indicating that all the traits are in balance for improvement.

Conclusion: Pedigree method is suitable for improving seed cotton yields and fiber quality. However, statistical check points are recommended with each proceeding generation to apply suitable selection pressure and monitor the gene action for each trait in each generation.

\section{Background}

Cotton (Gossypium hirsutum L.) is a cash crop of Pakistan contributing $0.8 \%$ in GDP and $4.5 \%$ in value addition of agriculture. Cotton has emerged as life line of Pakistan's economy but its production has been decreased by $17.5 \%$ in 2018 19 from last year. The decrease in cotton production was due to decrease in area for cotton production, unfavorable weather conditions and insect / pest attack (Economic Adviser's Wing 2019). Cotton fiber is largely produced natural fiber. Unlike the other natural fibers, cotton fiber is unicellular seed trichome (Boopathi et al. 2011). The quality of fiber is equally important to fiber yield of cotton crop to support the economy of the country. Cotton is mostly bread in Pakistan using pedigree method, where selection is performed in $\mathrm{F}_{2}$ and continued till $\mathrm{F}_{7}$ to get homozygous and homogenous population of newly developed cultivar. The plants of $F_{5}$ becomes $93.8 \%$ homozygous and plant breeders select best performing lines from $F_{5}$ (Acquaah, 2009).For genetic improvement, it is important to estimate the extent of genetic variation. The genetic information on broad sense (b. s.) heritability and genetic advance are very important to predict possible improvement in breeding material. Heritability is the proportion of variation in progeny that is inherited, while genetic advance is difference in mean phenotypic value of parents and offspring (Acquaah, 2009). Broad sense heritability and predicted genetic advance guide the plant breeder to apply an appropriate selection pressure for variety development. High genetic advance and high broad sense heritability estimates offers a most effective response to selection (Larik et al. 1997). In addition, correlation of seed cotton yield per plant with other morphological traits is critical for breeder to tackle of low yield of cotton crop. The correlation analysis also provides a good catalogue to predict the parallel change in one character at the expanse of the proportional change in the other character (Marwat, 2002; Ahmad et al. 2008).

An experiment was designed to predict heritability and genetic advance with different selection intensities in $\mathrm{F}_{5}$ generation of nine breeding lines. These breeding lines were established to develop cotton variety with high seed cotton yield and reasonable fiber quality. Correlation analysis was further carried out to predict the percent change in one trait by selecting for other trait. Mean comparison was also done to check the performance of all nine breeding lines. The study was aimed to determine the suitability of pedigree method for improving seed cotton yield per plant and fiber quality simultaneously.

\section{Materials And Methods}




\section{Experimental material and field layout}

Nine breeding lines from $\mathrm{F}_{5}$ were grown in an area of Cotton Research Station, AARI, Faisalabad in Randomized Complete Block design in triplicate during 2018-19 (Table 1). The seeds were sown with the help of dibbler on beds keeping plant to plant $30 \mathrm{~cm}$ and row to row $75 \mathrm{~cm}$ distances. Five plants of each genotypes were selected form each replication.

Table 1: Breeding lines used in experiment

\begin{tabular}{|ll|}
\hline Lines & Treatment \\
\hline Line-1 & CIM-595 $\times$ FH-Lalazar \\
\hline Line-2 & NS-161 $\times$ MNH-988 \\
\hline Line-3 & A-905 $\times$ MNH-988 \\
\hline Line-4 & Sitara-11 $\times$ FH-142 \\
\hline Line-5 & Sitara-11 $\times$ FH-168 \\
\hline Line-6 & MNH-988 $\times$ A-905 \\
\hline Line-7 & $1005(F h-142 \times$ Sitara-11) $\times$ FH-Lalazar \\
\hline Line-8 & $1035 /$ P4 x USGA_13-1111 \\
\hline Line-9 & 1046 x USGA_13-1111 \\
\hline
\end{tabular}

\section{Data recording}

Data were recorded for traits including seed cotton yield per plant (g), GOT (\%), fiber fineness (mic), fiber length (mm), fiber strength (g/tex), number of bolls plant ${ }^{-1}$, number of nodes to first fruiting branch, plant height $(\mathrm{cm})$, total number of monopodial and number of sympodial branches.

\section{Statistical analysis:}

The data was analyzed as per Steel et al. (1996) for analysis of variance. Heritability (broad sense) estimate was calculated from ANOVA table as the ratio of genotypic variance to total variance. Genetic advance was also calculated in percent at $10 \%$ and $5 \%$ selection intensity. Co-heritability was estimated to estimate the inheritance of two traits simultaneously (Acquaah, 2009). Tuckey test was also done to check the variability in the breeding lines. These analyses were done following Soomro et al. (2010). Correlation analysis was further carried out to check the association of traits with each other (Kwon and Torrie, 1964). STATISTIX 8.1 was used to do the statistical analysis.

\section{Results}

\section{Assessment of variability:}

There exist considerable variance among genotypes for all traits under consideration. These lines had highly significant differences for number of sympodial branches plant ${ }^{-1}$, seed cotton yield, number of bolls plant ${ }^{-1}$ and GOT. While, for some traits significant differences were observed in germplasm under consideration. These traits include fiber length, fiber fineness, fiber strength, number of monopodial branches plant ${ }^{-1}$, number of nodes to first fruiting branch and plant height. All the traits had higher phenotypic coefficient of variance compared to genotypic coefficient of variance (Table 2). The difference between phenotypic and genotypic coefficient of variance were high for all the traits except for GOT indicating the variation in these lines are due to environmental influence except for GOT which is due to genetic effect. 


\section{Mean Comparison:}

Tuckey test separated the genotypes in three groups for number of bolls per plant, fiber strength, number of monopodial and sympodial branches, fiber fineness, plant height and seed cotton yield per plant. The lines were divided into four diverse groups for GOT, while, number of nodes and fiber length showed no diversity (Table 3).

\section{Nature of gene action:}

All the traits showed medium to high broad sense heritability estimates. Fiber length, fiber fineness, fiber strength and GOT had low genetic advance combined with high heritability indicating non-additive gene action of these traits. Thus, delayed selection from these breeding lines or using these lines in another round of hybridization to get transgressive segregants is recommended to improve fiber quality traits and GOT. Plant height, number of nodes to first fruiting branch, monopodial branches plant ${ }^{-1}$ and number of bolls plant ${ }^{-1}$ had medium genetic advance and moderate heritability showing non-additive gene action controlling these traits. High heritability indicates the role of genes in final phenotypic expression but low and medium genetic advance indicates less gain by selection for these traits. Thus, late selection in advance breeding lines for final variety approval can improve plant height, number of monopodial branches plant ${ }^{-1}$ and number of nodes to first fruiting branch. Sympodial branches and seed cotton yield plant ${ }^{-1}$ had high genetic advance and high heritability showing additive gene action of these traits and pure line selection for these traits would be rewarding. Co-heritability values for all the traits are also high indicating possibility of simultaneous improvement of yield and quality traits. Genetic advance seems more promising at $5 \%$ selection intensity compared to $10 \%$ selection intensity (Table 2 ).

Table 2: Genetic variability and gene action of morphological traits

\begin{tabular}{|c|c|c|c|c|c|c|c|c|}
\hline & RMS & TMS & PCV & GCV & $\mathrm{H}^{2}$ & $\mathrm{GA}(5 \%)$ & GA $(10 \%)$ & $\mathrm{CO}-\mathrm{H}^{2}$ \\
\hline Degree of freedom & 2 & 8 & & & & & & \\
\hline Fiber length (mm) & 0.64 & $1.01^{\star}$ & 2.5 & 1.6 & 40.0 & 2.1 & 1.8 & 63.2 \\
\hline Sympodial branches/plant & 16.41 & $58.48 * *$ & 31.5 & 23.6 & 55.9 & 36.3 & 31.0 & 74.8 \\
\hline Bolls/ Plant & 39.46 & $202.19 * *$ & 24.1 & 17.6 & 52.9 & 26.3 & 22.5 & 72.8 \\
\hline Fiber strength (g/tex) & 8.77 & $16.60 *$ & 10.2 & 6.8 & 44.0 & 9.2 & 7.9 & 66.3 \\
\hline GOT \% & 0.02 & $12.24^{\star \star}$ & 5.2 & 4.8 & 84.1 & 9.0 & 7.7 & 91.7 \\
\hline Monopodial branches/plant & 0.10 & $0.67 *$ & 21.9 & 14.1 & 41.6 & 18.8 & 16.1 & 64.5 \\
\hline Fiber fineness (mic) & 0.06 & $0.27 *$ & 9.4 & 5.9 & 39.4 & 7.6 & 6.5 & 62.7 \\
\hline No. of nods/ plant & 0.69 & $2.39 *$ & 18.9 & 11.5 & 36.7 & 14.3 & 12.2 & 60.6 \\
\hline Plant height (cm) & 70.46 & $1398.85^{\star}$ & 16.5 & 10.2 & 38.2 & 13.0 & 11.1 & 61.8 \\
\hline Seed cotton yield/plant (g) & 7356.04 & $7303.81^{\star \star}$ & 34.6 & 25.5 & 54.3 & 38.7 & 33.1 & 73.7 \\
\hline
\end{tabular}

where RMS is replication mean sum of sequare, TMS is treatment mean sum of sequare, PCV is phenotyic coefficient of varience, GCV is genotypic coefficient of variance, $\mathrm{H}^{2}$ is broad sense heritability, GA (5\%) is expected genetic advance at $5 \%$ selection intensity, GA (10\%) is expected genetic advance at $10 \%$ selection intensity, $\mathrm{CO}-\mathrm{H}^{2}$ is coheritability, * is significant difference at $p=0.5$ and $* *$ is significant at $p=0.01$

Table 3: Mean comparison of genotypes for morphological traits using Tukey's test 


\begin{tabular}{|c|c|c|c|c|c|c|c|c|c|c|}
\hline Treatment0 & BPP & FS & GOT \% & NPP & MPB & FF & $\mathrm{PH}$ & SCY & SPB & $\mathrm{FL}$ \\
\hline $\begin{array}{l}\text { CIM-595×FH- } \\
\text { Lalazar }\end{array}$ & 41.3ab & 29.9ab & $38.3 d$ & $7.7 a$ & $2.6 a b$ & 4.3ab & 162.2ab & $262.0 a$ & $27.4 a$ & $30.1 \mathrm{a}$ \\
\hline NS-161×MNH-988 & $43.5 a b$ & $26.0 a b$ & $44.1 \mathrm{a}$ & $5.8 a$ & $3.5 a$ & $4.7 a$ & $134.6 \mathrm{~b}$ & 159.6ab & $13.0 \mathrm{~b}$ & $29.4 a$ \\
\hline A-905×MNH-988 & $51.0 a$ & $32.1 \mathrm{a}$ & $40.3 \mathrm{bcd}$ & $6.5 a$ & $2.9 a b$ & $4.2 \mathrm{ab}$ & 159.6ab & $142.3 b$ & $12.6 \mathrm{~b}$ & $29.8 \mathrm{a}$ \\
\hline Sitara-11×FH-142 & $26.6 b$ & $31.4 a b$ & $42.5 a b$ & $5.9 a$ & $3.3 a$ & $4.2 \mathrm{ab}$ & 164.7ab & 158.3ab & 18.2ab & $29.9 a$ \\
\hline Sitara-11×FH-168 & $34.7 a b$ & 31.0ab & $41.3 \mathrm{bc}$ & $5.6 a$ & $2.6 a b$ & $3.8 \mathrm{ab}$ & 198.9a & $123.7 b$ & $16.8 b$ & $29.8 a$ \\
\hline $\mathrm{FH}-988 \times \mathrm{A}-905$ & $45.2 a b$ & $29.8 a b$ & $42.7 a b$ & $6.7 a$ & $2.4 a b$ & $4.4 a b$ & 178.3ab & 220.0ab & $15.3 b$ & $28.6 a$ \\
\hline $\begin{array}{l}\text { 1005(Fh- } \\
\text { 142×Sitara-11)×FH- } \\
\text { Lalazar }\end{array}$ & $36.1 a b$ & $29.1 \mathrm{ab}$ & $39.7 \mathrm{~cd}$ & $7.2 a$ & $1.9 b$ & 4.3ab & 198.5ab & $112.7 \mathrm{~b}$ & $16.7 b$ & $28.6 a$ \\
\hline $\begin{array}{l}\text { 1035/P4xUSGA_13- } \\
1111\end{array}$ & $38.3 a b$ & $25.2 b$ & $38.2 d$ & $5.0 \mathrm{a}$ & $2.7 a b$ & $3.7 b$ & 151.7ab & 211.0ab & $16.0 \mathrm{~b}$ & $29.1 \mathrm{a}$ \\
\hline $\begin{array}{l}\text { 1046xUSGA_13- } \\
1111\end{array}$ & $52.7 a$ & 28.0ab & $41.8 \mathrm{abc}$ & $5.3 a$ & $3.0 a b$ & $3.8 a b$ & 185.0ab & 150.0ab & $14.0 \mathrm{~b}$ & $30.1 a$ \\
\hline VALUE & 19.7 & 6.5 & 2.5 & 2.7 & 1.3 & 0.9 & 64.32 & 116.23 & 10.14 & 1.69 \\
\hline GROUPS & 3 & 3 & 4 & 1 & 3 & 3 & 3 & 3 & 3 & 1 \\
\hline
\end{tabular}

Where PH is plant height, MPB is monopodial branches per plant, SPB is sympodial branches per plant, BPP is number of bolls per plant, NPP is number of nodes per plant, GOT\% is ginning out turn percentage, FL is fiber length, FS is fiber strength, FF is fiber fineness, SCY is seed cotton yield per plant and means with common letters do not differ significantly at $p=0.05$

\section{Correlation:}

Correlation analysis (Table 4) indicated highly significant negative correlation of monopodial branches plant ${ }^{-1}$ with number $^{-}$ of nodes to first fruiting branch (-0.52) and plant height (-0.54). While GOT had highly significant positive correlation with fiber fineness (0.42) and number of monopodial branches plant ${ }^{-1}(0.47)$. Number of nodes to first fruiting branch showed significant positive correlation with plant height (0.39) and sympodial branches plant ${ }^{-1}(0.40)$. Sympodial branches also came up with significant positive correlation with seed cotton yield plant ${ }^{-1}(0.42)$. Monopodial branches had positive significant correlation with fiber length (0.37).

Table 4: Correlation analysis of morphological and fiber quality traits 


\begin{tabular}{|llllllllll|}
\hline & PH & MPB & SPB & BPP & NPP & GOT\% & FL & FS & FF \\
\hline MPB & $-0.538^{\star *}$ & & & & & & & \\
SPB & 0.078 & -0.187 & & & & & & \\
\hline BPP & -0.085 & 0.007 & -0.223 & & & & & \\
\hline NPP & $0.394^{*}$ & $-0.515^{\star *}$ & $0.396 *$ & 0.093 & & & & \\
\hline GOT\% & -0.056 & $0.467 * \star$ & -0.348 & 0.006 & -0.171 & & & \\
\hline FL & 0.021 & $0.369 *$ & 0.115 & 0.022 & -0.088 & 0.04 & & \\
\hline FS & 0.319 & 0.075 & 0.062 & -0.092 & 0.206 & 0.102 & 0.273 & \\
\hline FF & -0.338 & 0.175 & -0.062 & -0.147 & 0.209 & $0.420 * *$ & -0.156 & -0.001 & \\
\hline SCY & -0.355 & 0.121 & $0.422^{*}$ & 0.142 & 0.147 & -0.206 & -0.178 & -0.061 & 0.005 \\
\hline
\end{tabular}

Where, PH is plant height, MPB is monopodial branches per plant, SPB is sympodial branches per plant, BPP is number of bolls per plant, NPP is number of nodes per plant, GOT\% is ginning out turn percentage, FL is fiber length, FS is fiber strength, FF is fiber fineness, SCY is seed cotton yield per plant, " $\star$ " is significant at $p=0.05$ and " $\star \star$ " is highly significant at $p=0.01$.

\section{Discussion}

Genetic diversity is prerequisite for variety development. Selection after hybridization is done to get genetic purity of superior genetic combinations in progeny lines. Progeny lines become $93.8 \%$ pure in $\mathrm{F}_{5}$ generation and where selection of superior lines is done more rigorously to get advance breeding lines. Genetic diversity in $\mathrm{F}_{5}$ lines can lead to the multiple variety development lately. The genetic variability seems to be sufficient in $F_{5}$. Earlier studies of cotton also indicated significant differences in $F_{2}$ generation (Eswari et al. 2011), in $F_{2}$ and $F_{3}$ generations (Soomro et al. 2010) and in varieties and $F_{1}$ hybrids (Ahmed et al. 2006; Khalid et al. 2018).

High phenotypic coefficient of variance of all traits than genotypic coefficient of variance indicates environmental influence on the extent of variation present in $\mathrm{F}_{5}$. However less differences in these variances indicates close association of genotypic and phenotypic expressions. Previous studies in cotton also indicated high phenotypic coefficient of variance and less differences between genotypic and phenotypic coefficient of variation (Gnanasekaran et al. 2018; Eswari et al. 2017)

Fiber length and number of nodes to first fruiting branch showed no grouping in mean comparison, while for GOT \% , genotypes were divided in four groups. Earlier study in cotton also grouped genotypes of $F_{1}, F_{2}, F_{3}$ and parents into groups on basis of mean comparison (Ahmed et al. 2006; Soomro et al. 2010). Seed cotton yield plant ${ }^{-1}$ and other traits grouped genotypes in $\mathrm{F}_{5}$ lines into three groups. The difference in the variation of traits in earlier studies is due to different generations under consideration.

Fiber length, fiber fineness, fiber strength and GOT had high heritability and low genetic advance indicating non additive gene action of these traits. Plant height, number of nodes, monopodial branches and number of bolls per plant showed nonadditive and over dominance types of gene action due to medium genetic advance and high heritability. High heritability indicates the role of genes in final phenotypic expression but low and medium genetic advance indicates less gain by selection for these traits. Only sympodial branches and seed cotton yield plant ${ }^{-1}$ showed additive gene action and continued pure line selection can result in improved seed cotton yield and more sympodial branches. Earlier studies of cotton also indicated additive gene action of seed cotton yield plant ${ }^{-1}$ and estimated the gene action of other morphological and fiber quality traits (Ahmed et al. 2006; Gnanasekaran et al. 2018; Eswari et al. 2011; Soomro et al. 2010; Kumar et al. 2019). Thus 
for improving staple length, fiber fineness, fiber strength and GOT another round of hybridization is needed to shuffle the genetic makeup of these traits. Delayed and rigorous selection till $F_{7}$ and $F_{8}$ can also give desired results.

Seed cotton yield plant ${ }^{-1}$ came up with positive correlation with number of sympodial branches plant ${ }^{-1}$ indicating that more sympodial branches in variety would yield more seed cotton yield. While, GOT showed positive correlation with monopodial branches and number of initial nodes plant ${ }^{-1}$. This indicates that more fiber yield can be gain by giving more importance to monopodial branches and the fiber in this case would be finer and long. Selection should proceed with less number of initial nodes to improve fiber quality. Earlier studies also indicated positive association of seed cotton yield with number of sympodial branches per plant (Rahman et al. 2013; Khalid et al. 2018). While positive connotation of GOT with fiber fineness are contradictory with earlier studies (Khalid et al. 2018) may be due to difference in genetic material.

\section{Conclusion}

Genetic variability in $\mathrm{F}_{5}$ is suitable for variety development. Seed cotton yield has additive gene action while all other traits came up with non-additive type of gene action. Correlation studies indicated selecting more of monopodial branches to improve fiber quality while more number of sympodial branches plant ${ }^{-1}$ to improve seed cotton yield plant ${ }^{-1}$. Increased selection pressure of up to $5 \%$ is more promising for more genetic gain. Thus, pedigree method practiced in cotton breeding is likely to improve fiber quality and seed cotton yield. However, continued statistical analysis are recommended for determining the selection pressure and gene action for improving targeted traits.

\section{Declarations}

\section{Ethics approval and consent to participate:}

Not applicable

\section{Consent for publication:}

Not applicable

\section{Availability of data and materials:}

Data analyzed in paper is available at corresponding author's hand

\section{Competing interests:}

No author has competing interest

\section{Funding:}

The Government of the Punjab Pakistan funded research.

\section{Authors' contributions}

*Author 1: Abia Younas

Conducted the research and write-up the contents

Author 2: Farrukh Illahi

Conducted the research and review the article

Author 3: Dr.Ghulam Sarwar 
Supervise the research and ensure smooth supplies during experimentation

Author 4: Iram Sharif

Review the article, done the fiber analysis

Author 5: Dr. Shahid Munir Chohan

Review the article and help in conducting the experiment

\section{Acknowledgements}

Dr. Zaheer Abbas, PhD scholar of Department of Parasitology University of Agriculture Faisalabad has checked the plagiarism and helps in review and refines the final copy of manuscript

\section{References}

Economic Adviser's Wing, Finance Division, Government of Pakistan. Pakistan Economic Survey 2018-2019. Retrived

from http://www.finance.gov.pk/survey/chapters_19/Economic_Survey_2018_19.pdf. 2019. Accessed 3 Mar 2020.

Boopathi, N. Manikanda, et al. "Marker-assisted breeding as next-generation strategy for genetic improvement of productivity and quality: can it be realized in cotton?." International journal of plant genomics 2011 (2011).

Acquaah, George. Principles of plant genetics and breeding. John Wiley \& Sons, 2009.

Larik, A. S., S. R. Ansari, and M. B. Kumbhar. "Heritability analysis of yield and quality components in Gossypium hirsutum

L." Pakistan Journal of Botany (Pakistan) (1997).

Marwat, NUK. Genetic analysis, combining ability and heterotic studies for yield, its components, nd fibre quality traits in upland cotton (Gossypium hirsutum L.) (Doctoral Dissertation, Sindh Agriculture University Tandojam).2002.

Ahmad, W., et al. "Genetic variability and correlation analysis in upland cotton." Sarhad Journal of Agriculture (Pakistan) (2008).

Steel, R. D., J. H. Torrie, and D. Dickey. "Principle and procedure of statistics. A biometrical approach. McGraw-Hills Book Companies." Inc., New York (1996).

Soomro, ZA, et al. "Heritability and selection response in segregating generations of upland cotton." Pakistan Journal of Agricultural Research 23.1-2 (2010).

Kwon, S. H., and J. H. Torrie. "Heritability and interrelationship among traits of two soybean populations." Crop sci 4.2 (1964): 196-198.

Eswari, KB, Sudheer K, Gopinath S and Rao MVB. Genetic variability heritability and genetic advance studies in cotton. Int. J. Development Res; 2017; 7, 10902-10904.

Ahmed, Hafiz Munir, et al. "Heritability and genetic advance as selection indicators for improvement in cotton (Gossypium hirsutum L.)." J. Biol. Sci 6.1 (2006): 96-99.

Khalid MA, Malik TA, Fatima N,et al. . Correlation for Economic Traits in Upland Cotton. Acta Scientific Agriculture. 2018; 2: 59-62 
Gnanasekaran, M., K. Thiyagu, and M. Gunasekaran. "Genetic variability heritability and genetic advance studies in cotton (Gossypium hirsutum I.)." Electronic Journal of Plant Breeding 9.1 (2018): 377-382.

Kumar, C. Praveen Sampath, et al. "Studies on Genetic Variability, Heritability and Genetic Advance in Cotton (Gossypium hirsutum L.)." Plant Archives 19.1 (2019): 618-620.

Rahman, Samia A., et al. "Cause and effect estimates for yield contributing and morphological traits in upland cotton (Gossypium hirsutum L.)." J. Agric. Res 51.4 (2013). 